\title{
PURIFICACIÓN PARCIAL DE LAS TOXINAS HI1, HI2 Y HI3 DEL VENENO DEL ESCORPIÓN Hadruroides lunatus KOCH, 1867 (SCORPIONIDA: VEJOVIDAE)
}

\author{
PARTIAL PURIFICATION OF TOXINS HI1, HI2 AND HI3 FROM Hadruroides \\ lunatus KOCH, 1867 SCORPION VENOM (SCORPIONIDA: VEJOVIDAE)
}

\author{
Enrique Escobar*, Carlos Rivera, Luz Tincopa y Dani Rivera
}

\section{Resumen}

Se han separado las proteínas del veneno del escorpión Hadruroides lunatus, por cromatografía de intercambio iónico en CM-Sephadex C-25 con buffer acetato de amonio 0,05M, pH 7, y se obtuvieron seis picos de proteína. Los ensayos de toxicidad de las fracciones colectadas han permitido identificar 3 toxinas que hemos denominado H11, Hl2 y H13, las cuales paralizan, respectivamente, insectos (Grillus sp.), crustáceos (Porcellio laevis) y la extremidad inoculada de ratones albinos. Las tres toxinas son de naturaleza básica, y carecen de actividad proteolítica y fosfolipásica. Adicionalmente, H13 aumenta los niveles plasmáticos de creatina kinasa, luego de ser inoculada en el músculo gastrocnemius de ratones albinos.

Por electroforesis en gel de poliacrilamida con dodecil sulfato de sodio (PAGE-SDS), se ha determinado que H13 muestra una sola banda proteica de 12,5 KDa, mientras que las otras toxinas poseen contaminantes proteicos.

Palabras clave: Toxina, Hadruroides lunatus, escorpión, veneno de escorpión.

\section{Abstract}

The proteins from the venom of the scorpion Hadruroides lunatus were separated by ionexchange chromatography on CM-Sephadex C-25 with 0,05M ammonium acetate buffer $\mathrm{pH}$ 7 , getting six protein peaks in the process. The toxicity tests allowed the identification of three toxins that were denominated H11, H12 y H13; which immobilize, respectively, insects (Grillus sp.), crustaceans (Porcellio laevis) and the inoculated limb of white mice. The three toxins are basic proteins and have no proteolitic or phospholipase activity. In addition, H13 increases the plasmatic level of creatine kinase after its inoculation in the gastrocnemius muscle of mice.

By PAGE-SDS, H13 shows only one protein band of 12,5 KDa, while the other toxins have protein contaminants.

Keywords: Toxin, Hadruroides lunatus, scorpion, scorpion venom.

* Laboratorio de Bioquímica y Genética Molecular. Facultad de Ciencias Biológicas. UNMSM. eescobarg@unmsm.edu.pe 


\section{Introducción}

Los escorpiones son animales que producen un veneno con el que paralizan a sus presas naturales, las cuales están constituidas principalmente por insectos y pequeños crustáceos; sin embargo, en el hombre, el efecto del veneno puede ser inocuo o fatal, dependiendo de la especie de escorpión. En este sentido, los escorpiones más peligrosos para el hombre pertenecen a los géneros Tityus (Norte y Sudamérica), Centruroides (México), Androctomus, Buthacus, Leiurus, Buthotus y Buthus (Mediterráneo y norte de África) y Parabuthus (Sudáfrica).

Los primeros estudios sobre los escorpiones del Perú se iniciaron hace más de 30 años (Aguilar, 1968; Aguilar y Meneses, 1970) y ellos fueron importantes porque permitieron identificar algunos de los efectos del veneno, especialmente de Hadruroides lunatus, así como establecer la distribución geográfica y diversidad de escorpiones hallados en el país, llegándose a describir hasta 29 especies agrupadas en 5 familias (Maury, 1974; Franke, 1977). Sin embargo, los venenos de estos escorpiones han sido poco estudiados, así, por ejemplo, de los venenos de $H$. charcasus y Brachistosternus ehrenbergi, existen tan sólo reportes únicos y por lo mismo muy preliminares y genéricos (Arboleda y col., 1973; Calderón y Aguilar, 1988). En el caso del veneno de H. lunatus, que es el que tiene mayor distribución, entre Áncash, Lima, Ica y Arequipa, se ha llegado a describir algunos de sus efectos tóxicos y farmacológicos (Cáceres et al., 1972; Zavaleta, 1983). Así tenemos que en 1972 se determinó que la inyección intramuscular del veneno de H. lunatus producía parálisis reversible en la extremidad inoculada de ratones albinos (Cáceres et al., 1972), y posteriormente se encontró que el mismo veneno también producía parálisis a Porcellio laevis, cuando se inoculaba en la cavidad celómica de estos crustáceos (Castro et al., 1981). Sin embargo, en todos estos estudios sólo se trabajó con el veneno total y por lo tanto las proteínas responsables de estos efectos no fueron aisladas ni identificadas.

En este trabajo estamos iniciando el estudio sobre la separación de las proteínas del veneno de H. lunatus y describimos la identificación y purificación parcial de tres toxinas con acción específica sobre Grillus sp. (H11), Porcellio laevis (H12) y ratones albinos (H13).

Nuestro interés en el estudio de los componentes bioactivos de los venenos de escorpión radica no sólo en dilucidar la manera como ellos actúan durante el envenenamiento, sino además en el potencial uso que pueden tener en diversos campos de la actividad humana como salud y agricultura.

\section{Material y métodos}

\section{Veneno}

Escorpiones $H$. lunatus de ambos sexos fueron colectados en el fundo "La Ayanguera", irrigación Santa Rosa, distrito de Sayán, Huaura, y mantenidos en nuestro laboratorio. El veneno extraído por presión manual de las glándulas venenosas fue colectado en capilares, desecado y conservado a $4{ }^{\circ} \mathrm{C}$.

\section{Separación de las proteínas del veneno}

$20 \mathrm{mg}$ de veneno de H. lunatus fueron disueltos en $2 \mathrm{ml}$ de buffer acetato de amonio 0,05M, pH 7 y los restos insolubles se eliminaron por centrifugación a $4000 \mathrm{rpm}$ durante 20 minutos. El sobrenadante $(1,8 \mathrm{ml})$ se aplicó a una columna de intercambio catiónico de CMSephadex C-25 (17 X 1,1 cm), utilizando como buffer de elución acetato de amonio 0,05 M pH 7. Las proteínas retenidas en la columna fueron eluidas agregando al buffer de corrida $\mathrm{NaCl}$ 0,25M y 0,6M. La corrida se realizó a temperatura ambiente y a un flujo de $8 \mathrm{ml} / \mathrm{h}$.

\section{Cuantificación de proteína}

El contenido proteico del veneno crudo y de las proteínas obtenidas durante la separación cromatográfica se determinó por el método de Lowry (1951), usando como proteína estándar albúmina bovina $0,1 \mathrm{mg} / \mathrm{ml}$. 


\section{Evaluación de la pureza y determina- ción del peso molecular}

La pureza y el peso molecular de las proteínas obtenidas fueron determinados por electroforesis en gel de poliacrilamida en condiciones denaturantes con dodecil sulfato de sodio (PAGE-SDS), (Laemmli, 1970). Como proteínas estándares se utilizaron albúmina bovina (66 KDa), ovoalbúmina (45 KDa) y lisozima (14,3 KDa); cada proteína a una concentración de $2 \mathrm{mg} / \mathrm{ml}$. En todos los casos las proteínas fueron teñidas con azul de coomassie $0,1 \%$.

\section{Toxicidad sobre grillos}

Con una jeringa Hamilton se inoculó $10 \mu \mathrm{l}$ de veneno crudo $(120 \mu \mathrm{g})$ o de las fracciones colectadas, en la cavidad celómica de Grillus sp. La toxicidad fue evaluada inmediatamente, teniendo en cuenta la parálisis producida durante el primer minuto después de la inoculación.

\section{Toxicidad sobre Porcellio laevis}

Fue ensayada inoculando $10 \mu \mathrm{l}$ de veneno crudo $(60 \mu \mathrm{g})$ o de las fracciones colectadas, en la cavidad celómica de Porcellio laevis. La inoculación se hizo a la altura del tercer segmento dorsal y se evaluó la parálisis producida en el primer minuto después de la inoculación.

\section{Toxicidad sobre ratones albinos}

Ratones albinos de $20 \mathrm{~g}$ de peso fueron inoculados intramuscularmente a nivel del músculo gastrocnemius con $100 \mu$ de veneno crudo $(600 \mu \mathrm{g})$ o de las toxinas en estudio (5 $\mu \mathrm{g}$ de H11, $10 \mu \mathrm{g}$ de H12 y $40 \mu \mathrm{g}$ de H13), e inmediatamente se evaluó la parálisis producida en la extremidad inoculada.

\section{Actividad miotóxica}

Ratones albinos de 18 a 20 g de peso fueron inoculados en el músculo gastrocnemius con $100 \mu \mathrm{l}$ de veneno crudo $(600 \mu \mathrm{g})$ o de cada una de las toxinas ( $5 \mu \mathrm{g}$ de H11, $10 \mu \mathrm{g}$ de $\mathrm{H} 12$ y $40 \mu \mathrm{g}$ de H13). Los ratones controles fueron inoculados con $100 \mu$ de buffer acetato de amonio 0,05 M pH 7. Después de 1 hora los ratones fueron anestesiados con éter e inmediatamente se colectaron $0,4 \mathrm{ml}$ de sangre, por punción cardiaca, y se mezclaron con $40 \mu \mathrm{l}$ de citrato de sodio 3,8\%, luego de lo cual se centrifugó por 10 minutos a $300 \times \mathrm{g}$ para separar el plasma. Para medir la actividad de creatina kinasa, $25 \mu \mathrm{l}$ de plasma se aplicaron a $1 \mathrm{ml}$ del kit de Creatina Kinasa de Pointe Scientific, registrándose el incremento en la absorbancia a $340 \mathrm{~nm}$ durante 5 minutos. La actividad fue expresada en IU/L, que es la cantidad de enzima que cataliza la transformación de $1 \mu \mathrm{mol}$ de substrato por minuto.

\section{Actividad de fosfolipasa}

Se evaluó cualitativamente usando el método de Vidal et al. (1972), el cual se basa en el retardo en el tiempo de coagulación de una emulsión de yema de huevo al ser calentada en un baño de agua a $100{ }^{\circ} \mathrm{C}$, luego de la acción enzimática. Se preparó una emulsión lipoproteica de yema de huevo en buffer Tris $\mathrm{HCl} 0.05 \mathrm{M} \mathrm{pH} 8$ (1:1 en volumen). A $1 \mathrm{ml} \mathrm{de}$ esta emulsión se añadió $0.1 \mathrm{ml}$ del veneno y luego de 15 minutos a $37^{\circ} \mathrm{C}$, se calentó a 100 ${ }^{\circ} \mathrm{C}$ y se midió el tiempo de coagulación. La liberación de ácido lisofosfatídico produce un incremento en el tiempo de coagulación con respecto a un blanco sin enzima.

\section{Actividad proteolítica}

La probable acción proteolítica fue estudiada incubando, por separado, el veneno crudo $(24 \mu \mathrm{g})$ o cada toxina $(0,5$ a $5 \mu \mathrm{g})$, con albúmina bovina $(40 \mu \mathrm{g})$, caseína $(50 \mu \mathrm{g})$, hemolinfa de arañas $(150 \mu \mathrm{g})$ o hemolinfa de $P$. laevis $(100 \mu \mathrm{g})$, en un volumen de $20 \mu \mathrm{l}$ con buffer acetato de amonio 0,05 M pH 7, durante 2 horas. La proteólisis se evaluó por PAGE-SDS observando la variación en el patrón electroforético de cada proteína usada como sustrato, al ser tratada con veneno crudo o cada toxina. 


\section{Resultados y discusión}

\section{Fraccionamiento del veneno y separa- ción de las toxinas}

Al pasar el veneno crudo de $H$. lunatus por la columna de CM-Sephadex C-25, se obtuvo un pico de proteína que eluyó directamente con el buffer de corrida. Posteriormente, al incorporar al buffer de corrida $\mathrm{NaCl} 0,25 \mathrm{M}$, se obtuvieron dos picos adicionales y finalmente con $\mathrm{NaCl} 0,6 \mathrm{M}$, eluyeron tres picos más. En la figura 1 se muestra el perfil cromatográfico con los seis picos obtenidos y la posición donde se detectaron las toxinas H11, H12 y H13. En este sistema todas las toxinas interactuaron con el gel y sólo fue posible separarlas con 0,25M de $\mathrm{NaCl}(\mathrm{Hl} 1$ y Hl2) y $0,6 \mathrm{M}$ de $\mathrm{NaCl}(\mathrm{Hl} 3)$. Esto nos indica que las tres toxinas a $\mathrm{pH} 7$ tienen carga positiva que les permite interactuar con los grupos carboximetil del gel cargados negativamente. Este hecho implica que el pI de las toxinas es mayor que 7,0 y por lo tanto se trata de proteínas básicas, siendo la menos básica la H11, y la más básica la H13.
La naturaleza básica de estas proteínas es una característica común de varias toxinas aisladas de venenos de escorpión, lo cual es aprovechado para separar esta clase de proteínas mediante cromatografía de intercambio catiónico a pH 7,0 (Borges et al., 1990).

Cabe mencionar que los nombres de las toxinas aquí estudiadas responden a la nomenclatura propuesta por Becerril et al. (1996), quienes han planteado denominar a cada toxina con las letras iniciales del nombre científico del escorpión de donde se ha aislado ( $\mathrm{Hl}$ para Hadruroides lunatus), seguido por un número particular de la toxina. En este caso el número empleado para cada toxina se ha asignado según el orden de elución durante la separación.

Por otro lado, el análisis por PAGE-SDS mostró la presencia de al menos 11 bandas proteicas en el veneno crudo y un número variable en cada uno de los seis picos obteni-

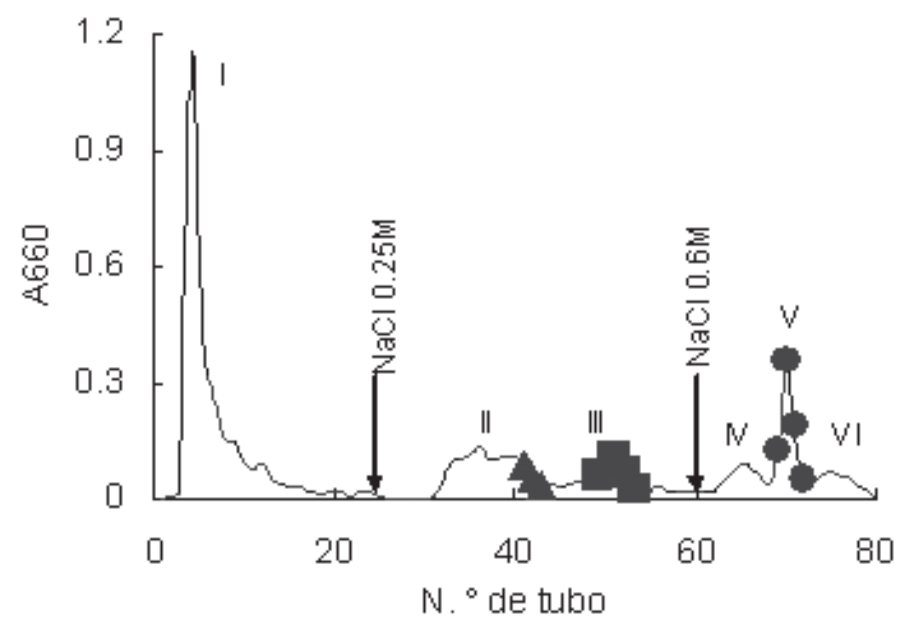

Figura 1. Separación de las proteínas del veneno de $H$. lunatus. Al pasar el veneno de $H$. lunatus por una columna de CM-Sephadex C-25 con buffer acetato de amonio 0,05M pH 7, se obtuvo inicialmente un pico de proteína (I). Cuando al eluente se incorporó $\mathrm{NaCl} 0,25 \mathrm{M}$, se obtuvieron 2 picos más (II y III) y finalmente al usar $\mathrm{NaCl} 0,6 \mathrm{M}$ se obtuvieron tres picos adicionales (IV, $\mathrm{V}$ y VI). Se indica la posición de las fracciones correspondientes a las toxinas $\mathrm{HI}$ 1 ( $\boldsymbol{\Delta}), \mathrm{HI} 2(\boldsymbol{\square})$ y HI3 (0), las mismas que se relacionan con la caída del pico II, el pico III y el pico V, respectivamente. 


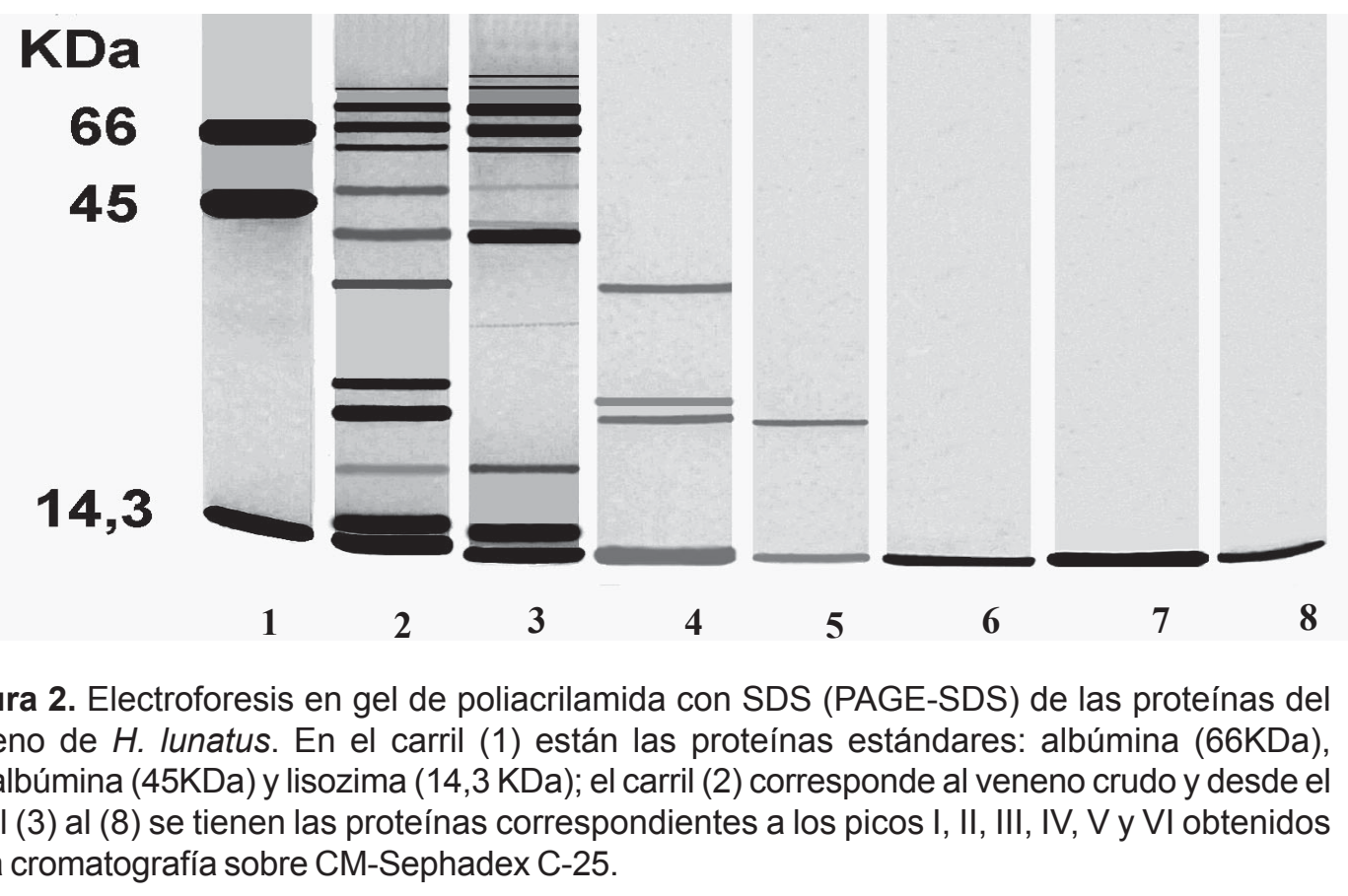

dos. Asimismo, la PAGE-SDS reveló que de las tres toxinas, sólo Hl3 mostró una sola banda homogénea de proteína con un peso molecular aproximado de 12,5 KDa (Fig. 2). Por el método de Lowry et al. (1951) se ha determinado que $\mathrm{Hl} 3$ representa $10,4 \%$ de la proteína total del veneno. En este aspecto queda pendiente separar hasta la homogeneidad $\mathrm{Hl} 1 \mathrm{y} \mathrm{Hl} 2$.

\section{Ensayos de toxicidad}

En relación a la toxicidad sobre grillos, sólo el veneno crudo $(120 \mu \mathrm{g})$ y las fracciones correspondientes a la caída del segundo pico produjeron parálisis en estos insectos. Cabe destacar que esta parálisis se produjo con tan sólo $0,5 \mu \mathrm{g}$ de proteína y durante el primer minuto después de la inoculación. Esta toxina (H11) mostró gran especificidad en la toxicidad hacia los grillos, y ningún efecto sobre $P$. laevis ni ratones albinos. Sin embargo, H11 eluyó con otras proteínas contaminantes. La primera toxina de escorpión, con actividad selectiva sobre insectos y que estructuralmente fue dilucidada, fue obtenida de Androctomus australis.
Esta toxina tiene 70 aminoácidos y no es tóxica para ratones (Darbon et al., 1982). Estas toxinas son particularmente interesantes por su posible utilidad como bioinsecticidas.

La toxicidad del veneno de $H$. lunatus sobre $P$. laevis fue reportada por Castro et al. en 1981. En este trabajo nosotros hemos encontrado que además del veneno crudo, las fracciones del tercer pico de proteína $(1 \mu \mathrm{g})$ producen parálisis y contractura corporal en $P$. laevis. Este efecto se produjo antes del primer minuto después de la inoculación, y la toxina responsable de este efecto fue denominada H12. Cabe señalar que esta toxina no tiene ningún efecto sobre insectos ni roedores. Sin embargo el análisis electroforético mostró que este pico contenía dos bandas de proteína. En otros venenos de escorpiones también se han encontrado toxinas específicas sobre crustáceos (Zlotkin et al., 1972), y otras como la Cn11 del veneno de Centruroides noxius, que además de ser tóxica para crustáceos, también lo es para insectos, pero con menos letalidad (Ramírez-Domínguez et al., 2002). 
Los resultados de los ensayos de toxicidad en ratones albinos mostraron que sólo el veneno crudo $(600 \mu \mathrm{g})$ y las fracciones del quinto pico cromatográfico $(40-10 \mu \mathrm{g})$, produjeron parálisis en la extremidad inoculada de los roedores. Esta acción paralizante sobre los roedores, que se manifiesta por la rigidez que adquiere la extremidad inoculada, y el arrastre de la misma cuando el animal se desplaza dura aproximadamente 20 minutos y fue reportada por primera vez en 1972, pero sólo fue determinada con el veneno crudo (Cáceres et al., 1972).

En este estudio nosotros hemos aislado y denominado $\mathrm{H} 13$, a la toxina responsable de este efecto. Es interesante señalar que la PAGE-SDS revela la presencia de una sola banda proteica de 12,5 KDa para esta toxina. En otros venenos de escorpiones también se han encontrado diversas toxinas para roedores, muchas de ellas con efectos letales. Así por ejemplo, en el veneno de Tityus discrepans se han identificado hasta 4 proteínas tóxicas a roedores (Borges et al., 1990).
Cabe señalar que, en general, las toxinas aisladas de otros venenos de escorpiones con acción en insectos, crustáceos y roedores han mostrado ser proteínas que bloquean principalmente canales iónicos de sodio y potasio (Ramírez-Domínguez, et al., 2002).

\section{Actividad miotóxica}

La evaluación de los niveles de creatina kinasa en el plasma de ratones tratados con cada una de las toxinas mostró que sólo H13 incrementó la actividad de creatina kinasa, hasta valores de $9400 \mathrm{UI} / \mathrm{L}$ después de 1 hora. Este valor en comparación al del control que es de $330 \mathrm{UI} / \mathrm{L}$, representa un aumento de 28 veces. Por su parte el veneno crudo produjo un aumento de creatina kinasa de $2600 \mathrm{UI} / \mathrm{L}$, mientras que $\mathrm{Hl} 1$ y $\mathrm{Hl} 2$ produjeron valores similares a los controles (Fig. 3).

Estos resultados indican que $\mathrm{H} 13$ es una miotoxina que no sólo paraliza la extremidad inoculada, sino que además probablemente afecta al sarcolema, permitiendo la salida de creatina kinasa. En Tityus serrulatus se ha

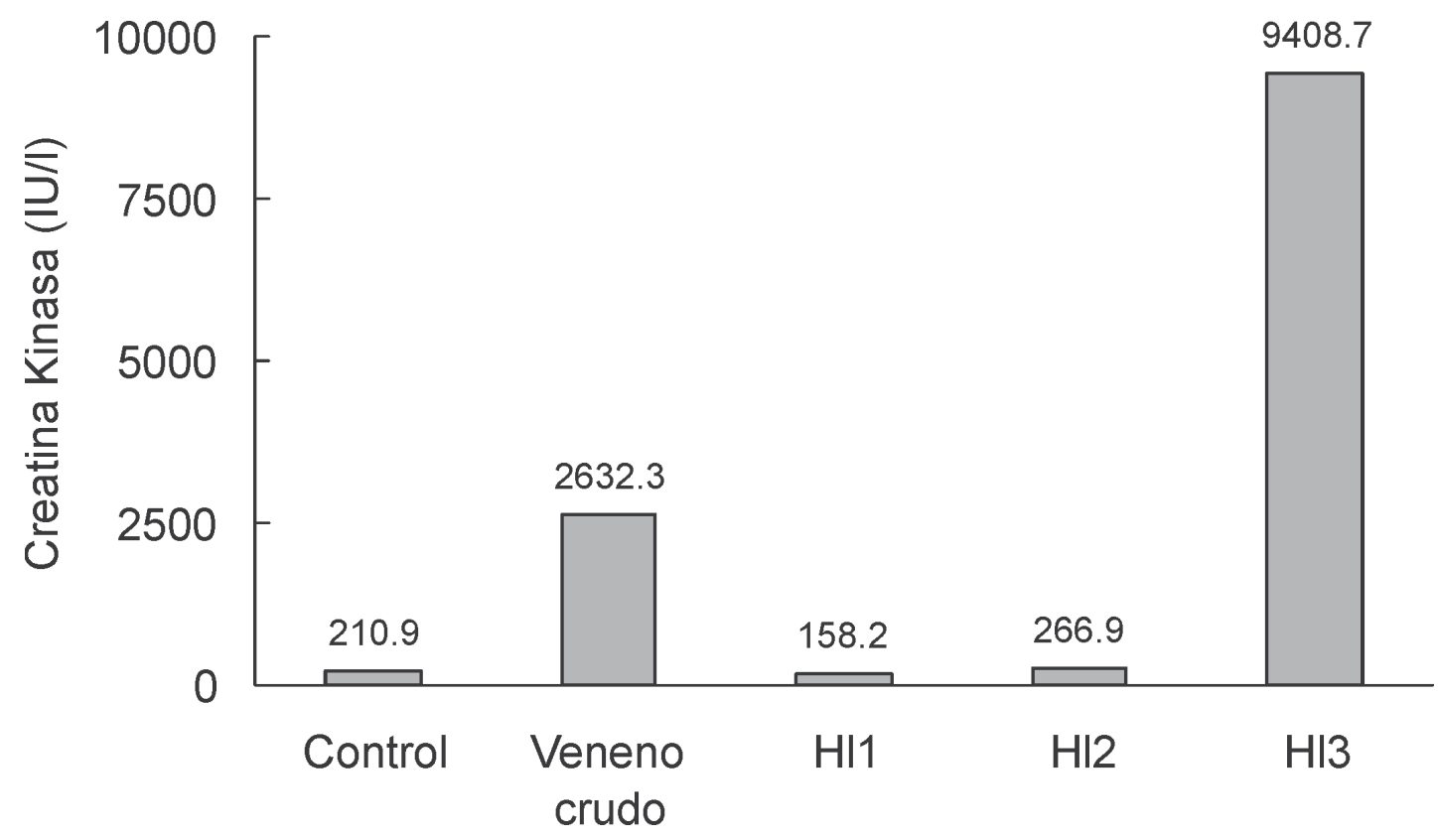

Figura 3. Actividad miotóxica del veneno crudo y de las toxinas $\mathrm{HI} 1, \mathrm{HI} 2$ y $\mathrm{HI} 3$ de $\mathrm{H}$. lunatus. Sólo la inoculación intramuscular de veneno crudo y HI3 produjeron la liberación de creatina kinasa en el plasma. 
demostrado que la Ts1 (tityustoxina-I), una neurotoxina, que bloquea canales de sodio y es letal para roedores, también provoca la liberación de creatina kinasa y otras proteínas musculares. Se cree que el incremento de la concentración de estas proteínas en el plasma podría deberse a un daño del tejido y/o una estimulación de mediadores químicos que podrían disparar su liberación (Correa et al., 1997).

\section{Actividad de fosfolipasa y actividad proteolítica}

Los ensayos de la actividad de fosfolipasa mostraron que, a diferencia del veneno crudo, ninguna de las toxinas aisladas tiene esta actividad, la cual más bien fue evidente en las fracciones del primer pico de proteína obtenido durante la separación cromatográfica. Esto significa que la toxicidad de las proteínas aisladas no depende de la actividad de fosfolipasa. Asimismo, al evaluar la probable acción proteolítica del veneno crudo de $H$. lunatus así como de cada una de las toxinas aisladas, sobre albúmina, caseína, hemolinfa de arañas y hemolinfa de $P$. laevis, se encontró que en todos los casos el patrón electroforético de las proteínas usadas como sustratos no fue modificado, lo cual demuestra que no sólo ninguna de las toxinas tiene actividad proteolítica, sino que igualmente el veneno de H. lunatus no es proteolítico. En este sentido el veneno de $H$. lunatus es similar a los venenos de Nebo hierichonticus y Vejovis spinigerus que no contienen proteasas (Rosin, 1972; Russell et al., 1968), pero diferente del veneno de Scorpio marus palmatus, en el que se ha detectado actividad proteolítica (Zlotkin et al., 1972). Estos resultados sugieren que el veneno de $H$. lunatus no participa en la digestión proteolítica de la presa.

En conclusión, en este trabajo hemos separado del veneno de $H$. lunatus las proteínas responsables de la toxicidad en insectos (H11), crustáceos (H12) y roedores (H13). Los estudios siguientes deben dirigirse a la purificación total de H11 y H12, y la evaluación de sus mecanismos de acción.

\section{Referencias bibliográficas}

Arboleda, E. Meneses, O. y Aguilar, P. 1973. Escorpiones y escorpionismo en el Perú. III. El veneno del "escorpión de Lambayeque". Revista Peruana de Entomología. 16 (1) 78-82.

Becerril, B.; Corona, M.; Coronas, F.; Zamudio, F.; Calderon-Aranda, E.; Fletcher, P.; Martín, B. and Posani, L. 1996. Toxic peptides and genes encoding toxin gamma of the brazilian scorpions Tityus bahiensis and Tityus stigmurus. Biochem. J. 313 : 753-760.

Borges, A.; Arantes, E. and Giglio, J. 1990. Isolation and characterization of toxic proteins from the venom of the Venezuelan scorpion Tityus discrepans (KARSCH). Toxicon 28 (9) : 10111017.

Cáceres, I.; Aguilar, P. y Meneses, O. 1972. Escorpiones y escorpionismo en el Perú. II. Efectos del veneno del "escorpión de los pedregales" en la costa central. Revista Peruana de Entomología. 15 (1) : 38-43.

Calderón, S. y Aguilar, P. 1988. Escorpiones y escorpionismo en el Perú. X: Efecto del veneno de Brachistosternus ehrenbergi sobre ratones albinos. Revista Peruana de Entomología. $30: 91-93$.

Castro, G.; Zavaleta, A. y Castro de la Mata, R. 1981. Variación estacional del veneno de Hadruroides lunatus (Koch) (Scorpionida: Vejovidae) y su actividad paralizante sobre Porcellio laevis Koch (Crustacea: Isopoda). Revista Peruana de Entomología 24 (1) 71-74.

Correa, M.; Sampaio, S.; Lopes, R.; Mancuso, L.; Cunha, O.; Franco, J. and Giglio, J. 1997. Biochemical and histopathological alterations induced in rats by Tityus serrulatus scorpion venom and its major neurotoxin tityustoxin-I. Toxicon 35 (7) : 1053-1067.

Darbon, H.; Zlotkin, E.; Kopeyan, C.; van Rietschoten, J. and Rochat, H. 1982. Covalent structure of the insect toxin of the North African scorpion Androctomus australis Hector. Inter. J. Peptide Protein Res. $20: 320-330$.

Francke, O. 1977. Escorpiones y escorpionismo en el Perú. VI. Lista de especies y claves para identificar las familias y los géneros. Revista Peruana de Entomología. 20 (1) 73-76.

Laemmli, U. 1970. Cleavage of structural proteins during the assembly of the head of bacteriophage $\mathrm{T} 4$. Nature 227 : 680-685. 
Lowry, O.; Rosebrough, N.; Farr, A. and Randall, R. 1951. Protein measurement with the Folinphenol reagent. J. Biol. Chem. 193 : 265275.

Maury, E. 1974. Escorpiones y escorpionismo en el Perú. IV: Revisión del género Hadruroides POCOCK 1893 (Scorpiones, Vejovidae). Revista Peruana de Entomología. 17 (1) : 9-21.

Ramírez-Domínguez, M.; Olamendi-Portugal, T.; García, U.; García, C.; Arechiga, H. and Posani, L. 2002. Cn11, the first example of a scorpion toxin that is a true of $\mathrm{Na}^{+}$currents in crayfish neurons. The Journal of Experimental Biology 205, 869-876.
Rosin, R. 1972. Venom, venom effects and poison gland of the scorpion Nebo hierichonticus. Cienc. Cult. 24, 246.

Russel, F.; Alender, C. and Buess, F. 1968. Venom of the scorpion Vejoris spinigerus. Science 159, 90.

Vidal, J.; Caltanes, P. and Stoppani, A. 1972. Some characteristic properties on phospholipases A from Bothrops neuwedii venom. Arch. Biochem. Biophys. 151-168.

Zavaleta, A. 1983. El veneno del escorpión: Bioquímica y Farmacología. Boletín de Lima, No.30, 75 88.

Zlotkin, E.; Lebovits, N. and Shulov, A. 1972. Toxic effects of the venom of the scorpion Scorpio maurus palmatus (scorpionidae). Riv. Parasitol. 33, 237. 